Bryn Mawr College

Scholarship, Research, and Creative Work at Bryn Mawr College

2008

\title{
The Use of Psychological State Words By Late Talkers at Ages 3, 4 and 5 Years
}

Eliza Carlson Lee

Leslie Rescorla

Bryn Mawr College, lrescorl@brynmawr.edu

Let us know how access to this document benefits you.

Follow this and additional works at: http://repository.brynmawr.edu/psych_pubs

Part of the Psychology Commons

\section{Custom Citation}

Lee, Eliza C., and Leslie Rescorla. "The Use of Psychological State Words by Late Talkers at Ages 3, 4 and 5 Years." Applied Psycholinguistics 29 (2008): 21-39, doi:10.1017/S0142716408080028.

This paper is posted at Scholarship, Research, and Creative Work at Bryn Mawr College. http://repository.brynmawr.edu/psych_pubs/1

For more information, please contact repository@brynmawr.edu. 


\title{
The use of psychological state words by late talkers at ages 3, 4, and 5 years
}

\author{
ELIZA CARLSON LEE and LESLIE RESCORLA \\ Bryn Mawr College
}

Received: January 6, 2006 Accepted for publication: February 12, 2007

\begin{abstract}
ADDRESS FOR CORRESPONDENCE
Leslie Rescorla, Department of Psychology, 101 North Merion Avenue, Bryn Mawr, PA 19010.

E-mail: 1rescorl@brynmawr.edu
\end{abstract}

\begin{abstract}
The use of four types of psychological state words (physiological, emotional, desire, and cognitive) during mother-child play sessions at ages 3, 4, and 5 years was examined in 30 children diagnosed with delayed expressive language at 24-31 months and 15 age-matched comparison children with typical development. The children's mean length of utterance, total words uttered, lexical diversity, and use of propositional complements were assessed. The late talkers used significantly more physiological state words at ages 3 and 4, but the two groups did not differ in their use of physiological state terms at age 5 . The late talkers used significantly fewer cognitive words than the comparison children at each age. The mothers of the late talkers made significantly fewer references to cognitive states than the mothers of the comparison children at each age. The delay in the emergence of cognitive state words in the preschool years may affect other aspects of late talkers' cognitive and social development.
\end{abstract}

Psychological state words are used to talk about internal states. Physiological words (such as sleepy and hungry), desire words (particularly want and need), and emotion words (such as happy and sad) are the earliest and most common psychological state words to appear in children's naturally occurring speech (Bartsch \& Wellman, 1995; Bretherton \& Beeghly, 1982). At around age 3, children begin to make references to cognitive states and to use words such as think, know, and guess (Bartsch \& Wellman, 1995; Shatz, Wellman, \& Silber, 1983; Tardif \& Wellman, 2000). Several studies have shown that parental use of cognitive state words is associated with children's later use of cognitive state terms (Bartsch \& Wellman, 1995; Jenkins, Turrell, Kogushi, Lollis, \& Ross, 2003; Ruffman, Slade, \& Crowe, 2002). Lee and Rescorla (2002) found that 3-year-old children with histories of expressive language delays as toddlers were delayed in the emergence of psychological state words compared to 3-year-olds with typical language development. The main question addressed by this study is whether these children with a history of language delay would "catch up" in their ability to use psychological state terms relative to children with typical language development by age 5 . 
Lee and Rescorla: Psychological state words

\section{LATE TALKERS}

Children who have delays in receptive and expressive language that cannot be attributed to a more primary disorder (e.g., mental retardation, autism, gross neurological dysfunction, physical impairment, hearing loss, or psychological disorder) are diagnosed as having specific language impairment (SLI; Bishop \& Edmundson, 1987; Rescorla \& Lee, 1999; Tallal, 1988). When children under the age of 4 meet the diagnostic criteria for SLI, they are often referred to as late talkers. Many late talkers have age-adequate receptive language, but some have delays in both receptive and expressive language. As summarized by Rescorla (2005), researchers who take a categorical view of language delay generally view late talkers as qualitatively different from children with SLI, primarily because late talkers appear to manifest a better outcome. In contrast, researchers who take a dimensional view of language impairment argue that late talkers and children with SLI fall on a spectrum of language impairment. Rescorla (2005) argues that late talkers generally have milder impairments, and hence, that the difference between the two groups is quantitative rather than qualitative.

\section{VOCABULARY DEVELOPMENT IN LATE TALKERS}

Late talkers are generally first identified because they lag behind age expectations in vocabulary acquisition (Rescorla \& Lee, 2000). For example, the 40 late talkers identified between 24 and 31 months by Rescorla (Rescorla, Roberts, \& Dahlsgaard, 1997) had a mean vocabulary on the Language Development Survey (LDS; Rescorla, 1989) of 20 words, in contrast to a mean reported vocabulary of 226 words in the comparison children with typical development of the same socioeconomic status (SES) background. Vocabulary delays manifested by late talkers at age 24 months tend to resolve by ages 3 to 4 (Fischel, Whitehurst, Caulfield, \& DeBaryshe, 1989; Paul, 1996; Rescorla et al., 1997; Thal, Tobias, \& Morrison, 1991). For example, only $21 \%$ of the late talkers in the Rescorla et al. (1997) longitudinal study scored more than $1 S D$ below age expectations on the Expressive One-word Picture Vocabulary Test (Gardner, 1981) by age 3 followup. Scarborough and Dobrich (1990) proposed that even when language delay is apparently resolved in early childhood, the illusory nature of this recovery may become apparent when the child encounters more complex language tasks.

When late talkers begin to acquire vocabulary, the types of words they use seem to match the types used by younger children with typical language development. Rescorla, Alley, and Christine (2001) used the LDS (Rescorla, 1989) to compare word frequencies in their sample of late talkers to those in a large community sample from Pennsylvania. The highest frequency words in the early lexicons of children with typically developing language were also among the first words acquired by late talkers. The average late talker at 34-36 months had a mean LDS vocabulary comparable to that of the average 24-month-old with typical development.

Diversity of vocabulary has not been previously studied in late talkers. However, children with SLI appear to have less diverse vocabularies than their peers with typical language development. Watkins Kelly, Harbers, and Hollis (1995) reported 
that children with SLI used a significantly fewer number of different words than their age-equivalent peers. In a study of nine children between the ages of 3 and 5 years with SLI, Goffman and Leonard (2000) showed that the children with SLI used a fewer number of different words per 50 utterances than the aged-matched comparison group at age 3 , but not at age 4 . A recently developed index of lexical diversity, voc $\mathrm{D}$, uses repeated calculations of the type-token ratio (TTR) over a range of tokens to show how the TTR varies in relation to sample size. This relationship is then compared to a mathematical model of TTR to yield D, an index of lexical diversity that may be less sensitive to sample size variation than the traditionally used TTR (McKee, Malvern, \& Richards, 2000). Owen and Leonard (2002) found that children with SLI between the ages of 3 and 7 had lower scores on voc $\mathrm{D}$ based on 100 utterances than age-matched, typically developing comparison children, although this group difference was not found when the voc $\mathrm{D}$ scores were based on 250 and 500 utterance samples.

Several studies have shown that children with SLI tend to have particular difficulty with verbs, over and above their general lag in lexical abilities (Leonard, 1998; Leonard, Miller, \& Gerber, 1999; Watkins, Rice, \& Moltz, 1993). For example, Conti-Ramsden and colleagues (Windfuhr, Faragher, \& Conti-Ramsden, 2002) reported that 4- and 5-year-old children with SLI produced fewer novel verbs and learned novel verbs at a slower rate than younger children with typical language.

\section{ACQUISITION OF PSYCHOLOGICAL STATE TERMS BY LATE TALKERS}

Lee and Rescorla (2002) examined the use of four types of psychological state words (physiological, emotional, desire, and cognitive) at age 3 in 31 late talkers and 21 age-matched comparison children with typical language development during mother-child play sessions. The late talkers and the comparison children did not differ in the use of emotional or desire terms, but the late talkers used significantly more physiological words and significantly fewer cognitive words than the children with typical development. Additionally, mothers in the late talker group made more references to physiological states and fewer references to cognitive states than mothers in the comparison group. The children's use of cognitive terms correlated significantly with measures of language ability, including mean length of utterance and the use of propositional complements.

To our knowledge, the only other study examining the psychological state lexicon in children with language delays was conducted by Johnston, Miller, and Tallal (2001), who compared 10 children with SLI (mean age $=4$ years, 11 months $[4 ; 11]$ ) to 10 children with typical language development (mean age $=$ $2 ; 8$ ) in both an age-matched and a language-matched comparison. Children with SLI used a significantly lower proportion of cognitive state terms, and showed less variety in their mental state lexicon than the age-matched children with typical language development, but did not differ significantly from the languagematched comparison children. Johnston et al. (2001) also found that children with SLI used communication predicates (e.g., show that and say that) more frequently than the comparison children. Johnston et al. (2001) suggested that the communication predicates refer to observable behaviors, whereas cognitive 
Lee and Rescorla: Psychological state words

state terms such as thinking and knowing do not. What is needed at this point is a clearer understanding of how late talkers use psychological words in the preschool years.

\section{RATIONALE FOR THE STUDY}

The current study examined the use of the psychological state lexicon in children with typical development and late talkers at ages 3, 4, and 5 years. The research addressed five basic questions:

1. How did the late talkers differ from children with typical language development in mean length of utterance (MLU), total number of words used, and lexical diversity at ages 3,4 , and 5 ?

2. Were there differences between the late talkers and the children with typical language development in terms of the frequency and types of psychological state words used as a percentage of total utterances at ages 3,4 , and 5 years?

3. To what extent was the children's use of psychological state words associated with language ability as measured by MLU, total number of words uttered, vocD and the use of propositional complements?

4. Were there differences in the mothers' use of psychological state words? Was the children's use of psychological state words related to their mothers' use?

5. In an MLU-matched comparison, did the late talkers differ from the comparison children in lexical diversity and use of psychological state words?

\section{METHOD}

\section{Participants}

Participants in this study included children and mothers from the Pennsylvania longitudinal study of expressive language delay (Rescorla, Dahlsgaard, \& Roberts, 2000; Rescorla et al., 1997; Rescorla \& Schwartz, 1990). The study included 30 late talkers and 15 age-matched comparison children with typical language development. These children were recruited to participate in the longitudinal study of expressive language delay through newspaper advertisements, notices to pediatricians, and a local infant lab. All but one of the children came from intact two-parent, middle to upper middle class White families.

The present study included only those children for whom transcripts were available for ages 3, 4, and 5 years, so that we would be able to use repeated measures analyses of variance (ANOVAs) for the analyses. The children in this study were similar on intake measures to the groups of late talkers and comparison children with typical development whose outcomes were reported in Lee and Rescorla (2002) and related studies (Rescorla et al., 1997, 2000), despite a slightly different sample size. The children included in this study were compared to the children excluded due to incomplete data using $t$ tests. These $t$ tests indicated no significant differences on any of the intake measures between the children included in the present study and the children not included. This indicates that attrition was not selective with respect to the initial status of the children.

All of the children in the late talker group were identified at ages 24-31 months as having normal nonverbal abilities and age-adequate receptive language but 


\begin{tabular}{lcc}
\hline \hline & $\begin{array}{c}\text { Late Talkers } \\
(n=30)\end{array}$ & $\begin{array}{c}\text { Comparison Children } \\
(n=15)\end{array}$ \\
\hline Intake age (months) & $26.57(2.56)$ & $25.73(2.25)$ \\
Hollingshead total & $53.33(13.71)$ & $51.80(10.76)$ \\
Reynell receptive $z$ score & & \\
$\quad t(43)=-3.70, p<.001$ & $0.17(0.55)$ & $0.83(0.59)$ \\
$t(43)=-13.05, p<.001$ & $-1.78(0.48)$ & $0.25(0.51)$ \\
LDS vocabulary & & \\
$t(43)=-13.89, p<.001$ & $19.07(23.24)$ & $225.07(75.05)$ \\
\hline \hline
\end{tabular}

Note: LDS, Language Development Survey.

significant delays in expressive speech. Thus, they all met diagnostic criteria for an expressive language disorder according to the American Psychiatric Association's (1994) Diagnostic and Statistical Manual of Mental Disorders - 4th Edition (DSM-IV). They had to have a Bayley Mental Development Index (MDI; Bayley, 1969) score of 85 or greater, a Reynell Receptive Language Scale (Reynell, 1977) score within 3 or 4 months of chronological age, a Reynell Expressive Language Scale score at least 6 months below chronological age, and significant delays in expressive speech that were documented in naturalistic observation and parental report. The children in the typical language comparison group had to meet these same criteria, except that they had to score within 3 or 4 months of their chronological age on the Reynell Expressive Language Scale.

Intake data for both groups are shown in Table 1. The children in the late talker and comparison groups were essentially identical in age and Hollingshead SES score (Hollingshead, 1978). The two groups were significantly different in the Reynell Receptive Language Scale $z$ score, which was obtained based on each child's raw score from the Reynell manual. Although the late talkers had receptive language skills within the normal range, the comparison children were advanced in receptive language skills. There was a striking difference in Reynell Expressive Language Scale $z$ scores between the two groups. On Rescorla's (1989) Language Development Survey the late talkers had a mean vocabulary of 19 words, in contrast to a mean vocabulary of 225 words for the comparison children.

\section{Procedure}

This study used videotapes of the children and their mothers playing at ages 3,4 , and 5 with the Fisher-Price Village, a toy that contains a wide variety of environments and equipment conducive to pretend play. The play sessions were both video- and audiotaped, while a speech-language pathologist present in the room took running notes of all utterances. Transcripts from these 30-min sessions were prepared from the tapes, with every utterance and action of the children and mothers recorded. The transcripts followed conventions established by the Children's Data Exchange System (CHILDES) consortium (MacWhinney, 1991). Each transcript was checked against the video- and audiotapes by at least one additional 
transcriber. Computerized Language Analysis (CLAN) procedures (MacWhinney, 1991) were used to identify a corpus of the first 100 complete child utterances, after excluding imitations, immediate self-repetitions, single-word "yes" or "no" responses to questions, memorized songs/rhymes, and unintelligible utterances. The CLAN MLU program was run on the 100-utterance corpus and the MLU scores were converted into $z$ scores using the benchmark mean and standard deviation values provided by Scarborough (1990). Lexical diversity was assessed using the $v o c \mathrm{D}$ utility (vocd $+\mathrm{t}^{*} \mathrm{CHI}{ }^{*}$.kwa $+\mathrm{f}$ ) of the CLAN language analysis program (MacWhinney, 2000). VocD is used as the measure of lexical diversity because it is assumed to be less sensitive to sample size effects than the TTR (McKee, Malvern, \& Richards, 2000).

The transcripts were coded for all children's and mothers' utterances containing psychological state words. Utterances containing psychological state words were examined to determine if the speaker made a genuine reference to a psychological state, rather than just using the word in a formulaic, conversational fashion (e.g., "I don't know" and "Know what?"). When these phrases were used in isolation, they were excluded from analysis. These phrases were not counted in the initial coding process, but a randomly selected sample of five transcripts from each group indicated that there were no significant differences between the two groups in their use of these phrases at each age. However, statements such as "I don't know what that is" were included in the analysis because the added complement indicates that the speaker was describing his/her state of knowledge about a particular object. All terms that occurred in the context of memorized songs or rhymes, such as "Happy Birthday," were excluded. This method of selecting terms for analysis is consistent with the procedures used by Shatz et al. (1983), Bartsch and Wellman (1995), and Lee and Rescorla (2002).

Utterances containing references to psychological states in each transcript were coded for speaker (mother/child) and type of word (physiological, emotional, desire, or cognitive). The children's use of propositional complements, the syntactic structure needed to support the use of many cognitive state words, was also assessed. Each speaker's use of psychological state words and propositional complements was calculated as a percentage of total utterances (100). The children's use of psychological state words and propositional complements was also analyzed as a proportion of total words uttered to account for the fact that the late talkers talked less than the children with typical language abilities. Results are presented based on percentage of total utterances. Unless otherwise indicated, results were comparable using both types of percentages.

For this study, physiological state words were defined as referring to internal states of the body, such as hot, hurt, and asleep. Emotional terms were defined as references to affective states and included words such as happy, sad, and mad. Words such as want and need were categorized as desire terms. Finally, cognitive state terms were defined as references to thoughts and beliefs, and included words such as think and know. A list of the psychological state words used by the children is shown in the Appendix.

Interrater reliability was computed for each of the coding categories by having a second rater code $25 \%$ of the transcripts (11 of each age). Overall, the coders agreed on $97 \%$ of the codings. Interrater reliability was also computed for each 
of the four coding categories. Agreement on the physiological state category was $96 \%$, and agreement on the cognitive state category was $92 \%$. Agreement on the emotional and desire terms was 94 and 99\%, respectively. These reliability figures also included agreement as to which utterances should be excluded because they were formulaic (e.g., "I don't know").

The late talkers were compared to the children with typical development in both an age-matched comparison and an MLU-matched comparison. In the agematched comparison, group differences in MLU, total number of words uttered, lexical diversity, the use of psychological state terms, and use of propositional complements were analyzed using 2 (Group) $\times 3$ (Time) repeated-measures ANOVAs and post hoc $t$ tests with Bonferroni corrections. Group differences in the mothers' use of psychological state terms were also analyzed using 2 (Group) $\times 3$ (Time) repeated-measures ANOVAs. Pearson correlations were used to determine the extent to which the children's and the mothers' use of psychological state terms were related. Correlations were also used to assess the relationship between the measures of language ability (MLU, total number of words uttered, voc $\mathrm{D}$, and the use of propositional complements) and the use of psychological state terms at each age. The MLU-matched groups were selected by excluding the late talker with the lowest MLU score at age 5 and the comparison child with the highest MLU at age 3 score so that the two groups had equivalent MLU scores: 4.03 (0.51) for the 5-year-old late talkers and 4.02 (0.54) for the 3-year-old comparison children with typical development. In the MLU-matched comparison, differences between these two groups were analyzed using $t$ tests with Bonferroni corrections.

\section{RESULTS}

\section{Language outcomes}

Table 2 contains scores for the two groups on a normed language measure at ages 3, 4, and 5. At ages 3 and 4, $z$ scores on the Reynell Expressive Language Scale are shown. At age 5, standard scores on the Patterned Elicitation Syntax Test (PEST; Young \& Perachio, 1983) are shown. These scores indicate that by the time they were seen at age 3, the late talker group scored within $1 S D$ of the mean on the Reynell Expressive Language Scale, but that the late talker group mean was significantly lower than the comparison group mean. The same pattern was evident at age 4 on the Reynell Expressive Language Scale and at age 5 on the PEST. Thus, the late talkers as a group had caught up to normative expectations by age 3 , but they continued to have weaker language skills than the children with typical developmental histories from the same demographic backgrounds through age 5 .

Table 2 also shows the group scores at ages 3, 4, and 5 for the language outcome measures analyzed for this study: MLU, total words uttered, and vocD. Results of a 2 (Group) $\times 3$ (Time) repeated-measures ANOVA conducted on MLU yielded significant effects for group, $F(1,42)=34.9, p<.001, \eta_{p}^{2}=.45$, time, $F(2,41)=$ $31.86, p<.001, \eta_{p}^{2}=.50$, and a significant Group $\times$ Time interaction, $F(2,41)=$ 11.77, $p<.001, \eta_{p}^{2}=.27$. At each age, the late talkers had significantly lower MLU scores than the comparison children with typical development, but the gap between the two groups narrowed over time. At age 3,10\% of the late talkers 
Lee and Rescorla: Psychological state words

Table 2. Language outcome measures for late talkers and comparison children at ages 3,4 , and 5 years

\begin{tabular}{|c|c|c|}
\hline & Late Talkers $(n=30)$ & Comparison Children $(n=15)$ \\
\hline \multicolumn{3}{|c|}{ Expressive Language Measures $^{a}$} \\
\hline Age 3 & $-0.73(1.07)$ & $1.77(0.80)^{* * *}$ \\
\hline Age 4 & $0.34(0.83)$ & $0.99(0.60)^{*}$ \\
\hline Age 5 & $88.72(31.48)$ & $115.70(10.66)^{* *}$ \\
\hline \multicolumn{3}{|c|}{ MLU } \\
\hline Age 3 & $2.37(0.92)$ & $4.16(0.73) * * *$ \\
\hline Age 4 & $3.69(0.62)$ & $4.67(0.88)^{* * *}$ \\
\hline Age 5 & $3.99(0.56)$ & $4.52(0.59)^{* *}$ \\
\hline \multicolumn{3}{|c|}{ Total Words } \\
\hline Age 3 & $280.50(116.31)$ & $445.80(94.41) * * *$ \\
\hline Age 4 & $349.77(58.72)$ & $429.27(92.57)^{* *}$ \\
\hline Age 5 & $381.57(56.63)$ & $391.93(72.29)$ \\
\hline \multicolumn{3}{|c|}{ VocD } \\
\hline Age 3 & $44.33(17.32)$ & $60.80(9.50)^{* * *}$ \\
\hline Age 4 & $58.56(12.51)$ & $71.53(12.37)^{* *}$ \\
\hline Age 5 & $67.21(12.52)$ & $71.88(13.43)$ \\
\hline
\end{tabular}

Note: MLU, mean length of utterance; $V o c \mathrm{D}$, a measure of lexical diversity using the vocd utility of the CLAN language analysis.

${ }^{a}$ Reynell Expressive Language Scale ( $z$ scores) at ages 3 and 4, Patterned Elicitation Syntax Test (standard scores) at age 5.

${ }^{*} p<.05{ }^{* *} p<.01 .{ }^{* * *} p<.001$.

scored within $1 S D$ of the mean for the comparison group. At ages 4 and 5, these percentages were 47 and 53\%. Thus, despite a significant group difference in MLU at each age, an increasingly large percentage of late talkers scored in the same range as the comparison children over time.

The total number of words uttered in the language sample of 100 utterances was assessed for the two groups of children at ages 3, 4, and 5. A 2 (Group) $\times 3$ (Time) repeated-measures ANOVA yielded significant effects for group, $F(1,42)=$ $19.24, p<.001, \eta_{p}^{2}=.31$, and a significant Group $\times$ Time interaction, $F(2,42)$ $=10.14, p<.001, \eta_{p}^{2}=.31$. The two groups differed significantly in their total number of words at ages 3 and 4 , but did not differ significantly at age 5. A significant group difference in total number of words was expected, given a fixed number of utterances and lower MLU scores in the late talker group.

Lexical diversity, or the richness of the children's overall lexicons, was examined using $v o c \mathrm{D}$, the measure of lexical diversity using the $v o c D$ utility of the 


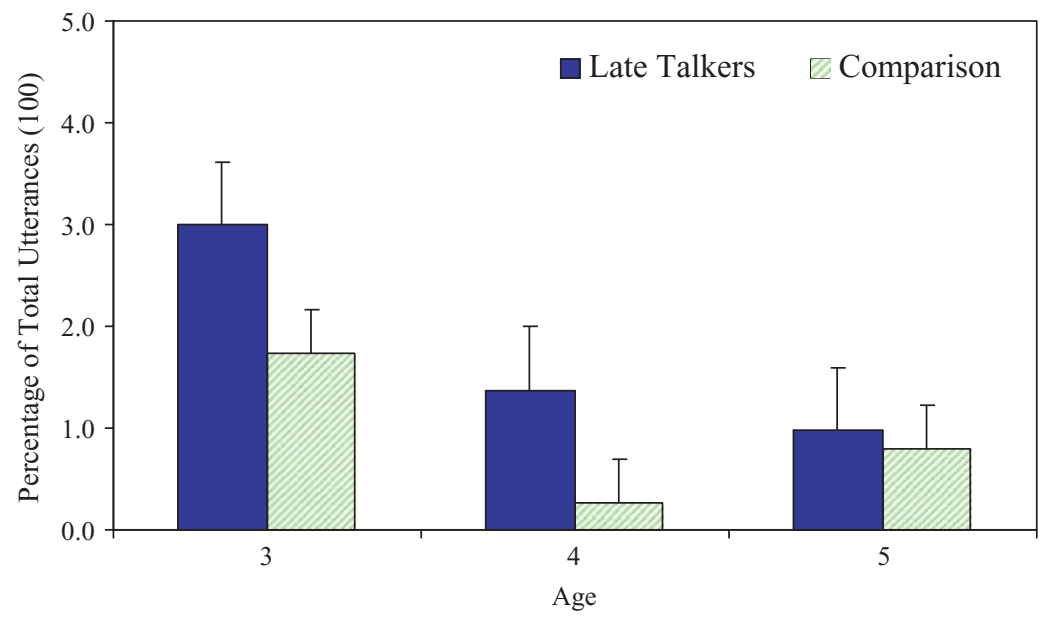

Figure 1. Children's use of physiological state terms (age-matched comparison). [A color version of this figure can be viewed online at www.journals.cambridge.org]

CLAN language analysis program (MacWhinney, 2000). A 2 (Group) $\times 3$ (Time) repeated-measures ANOVA yielded significant effects for time, $F(2,41)=13.67$, $p<.001, \eta_{p}^{2}=.32$, and group, $F(1,42)=13.09, p<.001, \eta_{p}^{2}=.24$, but a nonsignificant interaction. Lexical diversity increased significantly for both groups between ages 3 and 5. The two groups differed significantly on $v o c \mathrm{D}$ at ages 3 and 4 , but did not differ significantly at age 5 .

\section{Psychological state words used by children}

Psychological state terms accounted for an average of 2-3\% of the children's total words uttered. The children used between 0 and 12 physiological terms (such as hot, sleepy, hungry), 0-6 emotion terms (such as sad, mad, happy), 0-23 desire terms (such as want, need), and 0-17 cognitive terms (such as think, know) across the 100 utterances during the conversations with their mothers while playing.

As reported in Lee and Rescorla (2002), when the four types of psychological state terms (physiological, emotional, desire, and cognitive) were pooled together and analyzed as a percentage of total utterances, the late talkers did not differ from the comparison children with typical development at age 3 . The two groups also did not differ significantly in their use of psychological state terms at age 4. At age 5 the late talkers used significantly fewer total psychological state terms as a percentage of total utterances than the comparison children, $t(22,22)=-2.07$, $p<.05$, effect size $d=.70$ (calculated using the standard deviation for the whole sample).

When the frequency of each of the four categories of psychological state terms as a percentage of total utterances was analyzed separately, differences between the two groups emerged. Figure 1 shows the mean use of physiological state terms, such as hot, sleepy, and hungry, as a percentage of total utterances by the two 


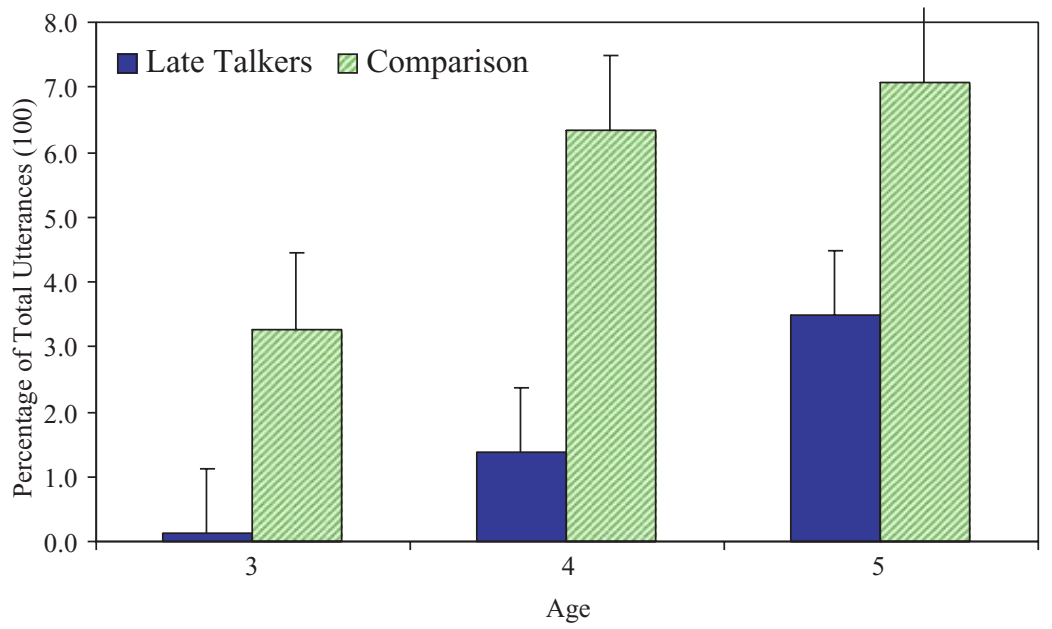

Figure 2. Children's use of cognitive state terms (age-matched comparison). [A color version of this figure can be viewed online at www.journals.cambridge.org]

groups of children at age 3, 4, and 5. A 2 (Group) $\times 3$ (Time) repeated-measures ANOVA yielded a significant effect for group, $F(1,43)=3.74, p=.04, \eta_{p}^{2}=.08$, and time, $F(1,43)=9.14, p=.004, \eta_{p}^{2}=.18$ for the children's use of physiological state terms as a percentage of total utterances. Post hoc $t$ tests indicated that the late talkers made significantly more references to physiological states than the comparison children at ages 3 and 4. Figure 1 shows that the late talkers' use of physiological state terms decreased over the 3 years, such that the two groups no longer differed in their use of physiological state terms by age 5 .

Results indicate that the late talkers and the comparison children did not differ in their use of emotional (such as mad or sad) or desire terms (want, need) as percentages of total utterances at ages 3, 4, or 5. Desire terms were the most frequently used psychological state terms for both groups at each age.

Figure 2 shows the mean frequencies of the children's use of cognitive state terms (including think, know, and pretend) as a percentage of total utterances at age 3, 4, and 5. A 2 (Group) $\times 3$ (Time) repeated-measures ANOVA yielded significant effects for group, $F(1,43)=48.96, p<.0001, \eta_{p}^{2}=.53$, and time, $F(1,43)=$ 47.87, $p<.0001, \eta_{p}^{2}=.53$. Using percentage of total utterances, the Group $\times$ Time interaction was not significant. However, the Group $\times$ Time interaction was significant using percentage of total words, $F(2,42)=5.35, p<.001, \eta_{p}^{2}=.04$. One-way ANOVAs conducted separately on each group indicated that both the late talkers' and the comparison children's use of cognitive state terms increased significantly between the ages of 3 and 5 years, $F(2,28)=35.21, p<.001, \eta_{p}^{2}=$ .42 , and $F(2,13)=25.27, p<.001, \eta_{p}^{2}=.50$, for the late talkers and the comparison group, respectively. This analysis of the two groups separately also showed that the late talkers' use of cognitive state terms increased faster over the 3 years than the comparison children's. The late talkers used virtually no cognitive 
Lee and Rescorla: Psychological state words

Table 3. Correlations between children's use of psychological state terms and language ability measures at ages 3, 4, and 5 years

\begin{tabular}{lccccc}
\hline \hline \multirow{5}{*}{$\begin{array}{c}\text { Age } \\
\text { (years) }\end{array}$} & MLU & Uttered & VocD & $\begin{array}{c}\text { Propositional } \\
\text { Complements }\end{array}$ \\
\cline { 3 - 5 } Physiological & 3 & -0.16 & -0.15 & -0.12 & -0.11 \\
& 4 & -0.11 & -0.416 & -0.01 & -0.26 \\
& 5 & -0.09 & 0.13 & 0.23 & 0.16 \\
Emotional & 3 & 0.11 & 0.05 & 0.23 & -0.15 \\
& 4 & -0.14 & -0.09 & -0.09 & -0.08 \\
Desire & 5 & 0.06 & 0.07 & 0.10 & 0.20 \\
& 3 & $0.51 * * *$ & $0.50 * * *$ & 0.03 & 0.24 \\
& 4 & 0.27 & 0.21 & 0.17 & 0.15 \\
Cognitive & 5 & 0.17 & 0.19 & -0.21 & -0.11 \\
& 3 & $0.64 * * *$ & $0.47 * *$ & 0.28 & $0.77 * * *$ \\
& 4 & $0.52 * * *$ & $0.45 * *$ & $0.46 * *$ & $0.79 * * *$ \\
& 5 & $0.55 * * *$ & $0.33 *$ & 0.17 & $0.75 * * *$ \\
\hline \hline
\end{tabular}

$* p<.05 . * * p<.01 . * * * p<.001$.

state terms at age 3; however, their use increased significantly each year. Figure 2 shows that at age 5, the late talkers' use of cognitive state terms was similar to the comparison children's use of the same terms at age 3. Post hoc $t$ tests indicated that the comparison children used significantly more cognitive state terms as a percentage of total utterances at each of the three ages.

\section{Use of psychological state terms and language ability}

The third question addressed by this study concerned the extent to which the children's use of psychological state words is associated with language ability, as measured by MLU, total number of words uttered, voc $\mathrm{D}$, and the use of propositional complements. Table 3 shows the correlations between the children's use of the four types of psychological state words and the four measures of language ability. The children's use of physiological and emotional state words was not significantly correlated with MLU, total number or words, voc $\mathrm{D}$, or the use of propositional complements at any of the three ages. At age 3, the children's use of desire words was significantly correlated with MLU and the total number of words $\left(r_{\mathrm{s}}=.51, p<.001\right.$ and $\left.r_{\mathrm{s}}=.50, p<.001\right)$. The children's use of cognitive state words was significantly correlated with $\operatorname{MLU}\left(r_{\mathrm{s}}=.64, .52\right.$, and $\left..55 ; p<.001\right)$ at ages 3, 4, and 5, respectively. The children's use of cognitive state words was significantly correlated with the total number of words uttered $\left(r_{\mathrm{s}}=.47, p<.01 ; r_{\mathrm{s}}=\right.$ $\left..45, p<.01 ; r_{\mathrm{s}}=.33, p<.05\right)$ at ages 3,4 , and 5 , respectively. The vocD and the use of cognitive state words were significantly correlated at age $4(r=.46, p<.05)$.

The largest correlations were those between use of cognitive state words and use of propositional complements, with $r_{\mathrm{s}}=.77, .79$, and $.75(p<.001)$ at ages 3 , 4 , and 5, respectively. Figure 3 shows the mean use of propositional complements 


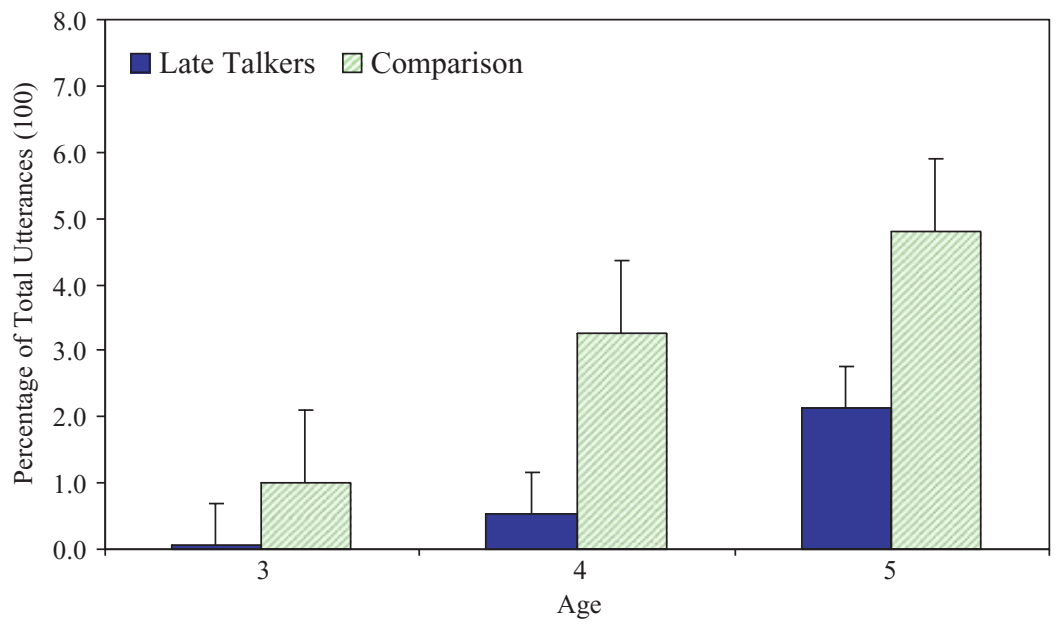

Figure 3. The use of propositional complements by children (age-matched comparison). [A color version of this figure can be viewed online at www.journals.cambridge.org]

as a percentage of total utterances for the two groups of children at ages 3,4 , and 5. A 2 (Group) $\times 3$ (Time) repeated-measures ANOVA yielded significant effects for group, $F(1,43)=31.09, p<.0001, \eta_{p}^{2}=.42$, and time, $F(1,43)=$ $61.60, p<.0001, \eta_{p}^{2}=.59$. At each age, the comparison children used significantly more propositional complements than the late talkers. The children's use of propositional complements increased significantly between the ages of 3 and 5 years for both the late talkers and the comparison children, $F(2,28)=16.73$, $p<.0001, \eta_{p}^{2}=.20$, and $F(2,13)=34.65, p<.0001, \eta_{p}^{2}=.31$, for the late talkers and the comparison group, respectively. Figure 3 shows that at age 5, the late talkers' use of propositional complements is lower than that of the comparison children at age 4 . At age 3, only 2 of the 30 late talkers $(7 \%)$ demonstrated an ability to use propositional complements, compared to 6 out of the $15(40 \%)$ comparison children. At age 4, 10 (33\%) of the late talkers and $14(93 \%)$ of the comparison children used propositional complements. At age 5, 17 (55\%) of the late talkers and $15(100 \%)$ of the comparison children demonstrated an ability to use propositional complement syntax.

Most but not all of the cognitive state terms require the use of a propositional complement. For example, the verbs pretend and remember were used to refer to mental acts without the use of propositional complements. In addition, propositional complements were used with noncognitive state verbs (as in, "Did you say that we were going to the playground?"). The words know, think, and pretend were the most frequently used cognitive state terms. The way in which the children used these terms and propositional complements changed over time, as can be seen in the following examples:

Late talker (Age 3): "I'm pretending."

Typically developing child (Age 3): "Her said her thinks it is a table."

Late talker (Age 4): "I know what this ladder is for." 
Typically developing child (Age 4): "I thought that the policeman was riding a motorcycle."

Late talker (Age 5): "I'm just pretending, Mom."

Typically developing child (Age 5): "Let's pretend that he knew somebody was coming over and he heard his motorcycle."

At ages 4 and 5, the comparison children in this sample began to use propositional complements after the cognitive state words, as in "He didn't know that the policeman was coming." They also used contrastives to express false belief, as in "The baby thinks this is a park, but it is a jail." The comparison children made references to the cognitive states of the toys as they played, as well as to their own and to their mother's cognitive states. The examples above show that although the late talkers' use of cognitive state terms increased each year, the way in which they used these terms did not change noticeably. The late talkers rarely used propositional complements with the cognitive state terms; at age 5 propositional complements were just emerging in a few of the late talkers' language, as in the example "I just thought be alright."

\section{Mothers' use of psychological state words}

The fourth question addressed by this study concerned the mothers' use of psychological state words and the extent to which the children and mothers' use of these words was related. A 2 (Group) $\times 3$ (Time) repeated-measures ANOVA conducted on the mean frequencies of the mothers' use of the four types of psychological state terms yielded a significant effect for group, $F(1,43)=16.20, p<.001$, $\eta_{p}^{2}=.27$. Post hoc $t$ tests indicated that at ages 3 and 5, the mothers of the children in the comparison group made significantly more references to psychological states than the mothers of the late talkers. When the four types of psychological state words were analyzed separately, the mothers' use followed a similar pattern to that of the children. The mothers of the two groups of children did not differ in their use of emotion and desire terms at any of the three ages.

A 2 (Group) $\times 3$ (Time) repeated-measures ANOVA conducted on the mean frequency of the mothers' use of physiological state words yielded a significant Group $\times$ Time interaction, $F(2,42)=4.51, p<.05, \eta_{p}^{2}=.18$. The mean number of references to physiological states made by the mothers of the late talkers decreased significantly over the 3 years, as indicated by a one-way ANOVA, which yielded a significant effect of time for the mothers of the late talkers, $F(2,28)=7.63, p$ $=.002, \eta_{p}^{2}=.31$. Post hoc $t$ tests indicated that at ages 3 and 4 , the mothers of the late talkers used significantly more physiological state terms than the comparison group mothers, but by age 5 , there was no significant difference between the two groups of mothers.

Results of a 2 (Group) $\times 3$ (Time) repeated-measures ANOVA conducted on the mean frequencies of the mothers' use of cognitive state terms yielded a significant effect for group, $F(1,43)=28.7, p<.0001, \eta_{p}^{2}=.40$. Post hoc $t$ tests indicated that the mothers of the late talkers made fewer references to cognitive states than the mothers of the comparison children at each age. The mothers of the late talkers increased their use of cognitive state terms over the 3 years, whereas the mothers of the comparison children did not. 
Lee and Rescorla: Psychological state words

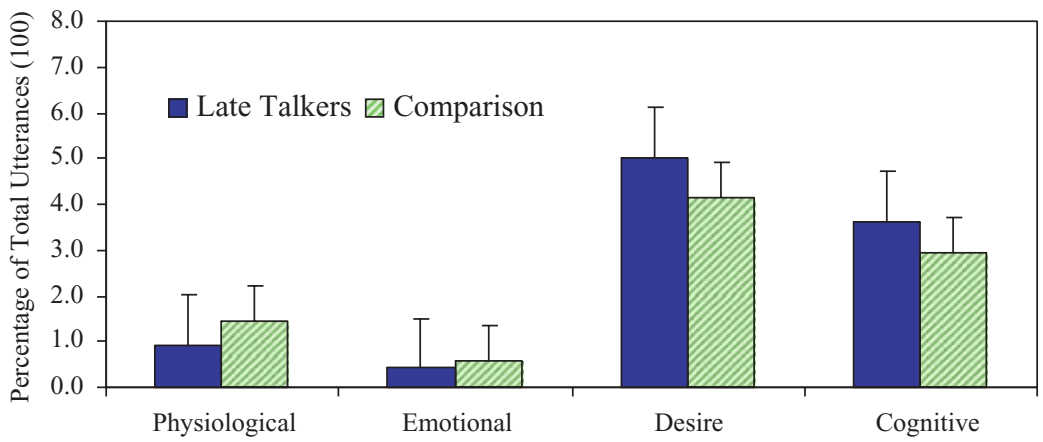

Figure 4. Children's use of psychological state words (mean length of utterance matched). [A color version of this figure can be viewed online at www.journals.cambridge.org]

Pearson product-moment correlations were performed to determine the extent to which the children's use of psychological state terms was correlated with the mothers' use. For the two groups combined at age 3, the children's use of desire and cognitive terms was significantly correlated $\left(r_{\mathrm{s}}=.58\right.$ and $.45, p<.001$ with two-tailed significance) with their mothers' usage of the same terms. At age 4, the children's use of all four types of psychological state terms was significantly correlated with the mothers' use $\left(r_{\mathrm{s}}=.38, p<.01\right.$ for physiological terms; $r_{\mathrm{s}}=$ $.77, p<.001$ for emotional terms; $r_{\mathrm{s}}=.53, p<.001$ for desire terms; and $r_{\mathrm{s}}=.36$, $p<.01$ for cognitive terms). At age 5, only the children's use of physiological state terms was significantly correlated with their mothers' usage $(r=.33, p<.05)$.

Pearson correlations were also used to determine the relationship between the mothers' use of cognitive state terms when the children were 3 and the children's later use of the same terms. The mothers' use of cognitive state terms when the children were 3 was positively and significantly correlated with the children's use of the same terms 1 and 2 years later $(r=.44, p<.01$ and $r=.51, p<.001$ for the children at ages 4 and 5 years, respectively). Partial correlations showed that the mothers' use of cognitive state terms when the children were 3 was still positively and significantly correlated with the children's use at age 5 ( $r=.36$, $p<.01$ ), when controlling for the children's use of cognitive state terms at age 3 . The same partial correlation was not significant for the children's use at age 4 $(r=.20, p=.20)$.

\section{MLU-matched comparison}

When the 5-year-old late talkers were compared to the 3-year-olds in the comparison group with equivalent MLU scores, the results indicated no significant differences between the two groups in overall lexical diversity as measured by voc $\mathrm{D}, t(32,44)=1.97, p>.05, d=.57$, using whole group $S D$. As seen in Figure 4, the MLU-matched groups did not differ significantly in their use of any of the four types of psychological state words. Despite their advanced age, the 5-year-old late talkers did not make more references to cognitive states than the 3 -year-old comparison children. In addition, there were no significant differences 
between the 5-year-old late talkers and the language-matched comparison children in their use of propositional complements, $t(41)=2.25, p=.03, d=.69$.

The mothers of the 5-year-old late talkers did not differ from the mothers of the 3-year-old comparison children in their use of physiological, emotional, or desire terms, but they did make significantly fewer references to cognitive states than the mothers of the 3-year-old comparison children, $t(41)=-2.65, p<.01$, $d=.81$.

\section{DISCUSSION}

This study examined the children's use of four types of psychological state words (physiological, desire, emotion, and cognitive) at ages 3, 4, and 5. Consistent with other studies (Bartsch \& Wellman, 1995; Bretherton \& Beeghly, 1982), psychological state terms accounted for $2-3 \%$ of the total words uttered by the children at each age.

In the age-matched comparison, the late talkers and the children in the typically developing comparison group did not differ in their overall use of psychological state words, nor in the use of emotion or desire terms at any age. The late talkers did use significantly larger percentages of physiological words at ages 3 and 4 , but not at age 5. Because physiological state words are among the earliest psychological state words acquired in typically developing children (Bretherton \& Beeghly, 1982), their relative preponderance in the conversations of the late talkers at ages 3 and 4 is an indication of a developmental lag in their acquisition of psychological state words.

The most striking difference found between the late talkers and the typically developing children was in their use of cognitive state terms. At each of the three ages, the late talkers used significantly fewer cognitive state terms as a percentage of their total utterances in this language sample, although the late talkers' use of these terms did increase each year. To account for the fact that the late talkers used fewer words than the children with typical language development, the analyses were conducted with the psychological state words calculated as a proportion of total words uttered and the results were the same, with the exception of the Group $\times$ Time interaction for cognitive terms, which was only significant using percentage of words.

When the age 5 late talkers were matched on MLU with the age 3 comparison children, the 5-year-old late talkers did not differ from the 3-year-old children with typical development in their use of cognitive state terms, indicating a 2-year lag in the late talkers' acquisition of cognitive state terms such as think and know. This finding is consistent with those reported by Johnston et al. (2001), who found that 4- and 5-year-olds with SLI used cognitive state terms at the same rates as typically developing 2.5-year-olds. The 5-year-old late talkers also did not differ from the 3-year-old children with typical development in lexical diversity, in use of propositional complements, or in MLU (on which they were matched). These findings suggest that the lag in use of cognitive state words in the late talkers was commensurate with their lag in other aspects of expressive language development. Despite the fact that the 5-year-old late talker group scored in the average group on normed language tests, they still were significantly behind peers from the same SES background in many important aspects of expressive language development. 
The late talkers in this sample were also delayed in their ability to use propositional complements. At age 5, only 17 (55\%) of the late talkers demonstrated an ability to use propositional complements, whereas all of the comparison children used this syntactic form. The most frequently used cognitive state terms in the language samples, know and think, require the use of a propositional complement when used to express cognitive states, as in the sentence, "I know that he is a firefighter." In contrast, pretend is a cognitive state term that can be used without a propositional complement to express a state of mind, as in the statement, "I'm pretending." The late talkers in this study tended to use the word pretend in this manner more frequently than the comparison children. This suggests that pretend may be an emergent form of cognitive state expression that is more accessible to the late talkers because it does not require a propositional complement.

Cognitive state terms (think, know, pretend, remember, etc.) are not observable behaviors; therefore, their meaning must be inferred from the language itself (Johnston et al., 2001). Studies have shown that children with SLI may use verbal schemes less efficiently, or rely on nonverbal symbolic schemes more than children with typical language development (Sturn \& Johnston, 1999). This may make it more difficult for children with SLI to understand the meaning of words for which nonverbal symbolic schema are unavailable. This notion is also consistent with Johnston and Kamhi's (1984) report that the children with language impairment in their study talked more about ongoing events that were more readily observable and less about intentions or necessities than MLU-matched control children.

Research has shown that children's use of cognitive state terms is related to their mother's use of these terms (Bartsch \& Wellman, 1995; Jenkins et al., 2003; Ruffman et al., 2002). In this study, the mothers of the late talkers made more frequent references to physiological states than the mothers of the comparison children when the children were 3 and 4 years of age than the mothers of the typically developing children. No differences were found in the mothers' use of desire and emotion terms at any age. At each age, the mothers of the late talkers used fewer cognitive state terms than the mothers of the typically developing children. This difference was even more striking when the children were matched for language ability. In this analysis, the mothers of the 5-year-old late talkers made fewer references to cognitive states than the mothers of the 3-year-old comparison children.

At ages 3 and 4, the mothers' and children's use of psychological state terms was significantly correlated. At age 5 , however, their use of psychological state terms was not correlated. It is possible that this is indicative of a developmental change in the play between the mothers and children, whereby the 5-year-old children tended to play more independently while the mothers watched and commented less. Based on our correlational data, we cannot determine if the mothers were responding to the late talkers' level of psychological state term usage or if the children's usage was shaped by the mothers' input. Other research does support the notion that mothers' use of psychological state terms predicts their children's later use of the same terms (Bartsch \& Wellman, 1995; Jenkins et al., 2003; Ruffman et al., 2002). In the present study, the mothers' use of cognitive state terms when the children were 3 was significantly correlated with the children's use of cognitive state terms at ages 4 and 5, which suggests that the mother's input plays a role in the children's use of cognitive state terms. 
The results of this study must be considered in light of certain limitations inherent in the sample used. The late talkers in this sample were all children with average or better nonverbal abilities, good receptive language, normal socialemotional development, and middle to upper middle class family backgrounds. The comparison group of children with typical development was matched at intake on SES and nonverbal ability with the late talker group. In a more diverse sample of late talkers, the delay in the use of cognitive state words might have been even more substantial. In contrast, if the late talkers in this study had been compared with a group of typically developing children from more diverse back grounds who had less advanced skills than our comparison group, the group differences might have been smaller. Generalizability of our results is thus limited to children with average or better nonverbal cognitive abilities from middle to upper SES families.

In conclusion, children with a history of expressive language delay showed significant delays in the lexicon used to talk about psychological states. At age 5, the children with language delays showed a 2-year lag in their use of cognitive state words such as think and know. This lag in the ability to talk about cognitive states may be related to the late talkers' limited ability to use propositional complements as well as the fact that cognitive state verbs represent behaviors that are not observable, which may make them more difficult for children with language delays to acquire. In addition, the mothers of the late talkers in this study used fewer cognitive state words in conversations with their children than the mothers of the typically developing children. Delay in talk about cognitive sates may affect other aspects of late talkers' cognitive, social, and emotional development. A developmental lag in the ability to talk about thoughts and beliefs may have a negative impact on social understanding and peer interaction, which becomes important in the later preschool years as children enter more formal educational environments.

\section{APPENDIX}

Psychological state words used by children

\begin{tabular}{llll}
\hline \hline Physiological & Emotion & Desire & Cognitive \\
\hline Sleep & Happy & Want & Think \\
Asleep & Sad & Need & Know \\
Wake up & Mad & Like & Pretend \\
Awake & Upset & Love & Guess \\
Died/dead & Cry & Hate & Mean \\
All better & Angry & & Make believe \\
Okay & Scared & & Bet \\
Toilet references & Worried & & Forget \\
Hot & Relax & & Sure \\
Broken & & & Understand \\
Hurt & & & Believe \\
Booboo & & & Remember \\
\hline \hline
\end{tabular}


Lee and Rescorla: Psychological state words

\section{ACKNOWLEDGMENTS}

This research was supported by grants from the Bryn Mawr College Faculty Research Fund (to L.R.) and from the National Institutes of Health (NICHD Area Grants 1-R15HD22355-01 and NIDCD R01-DC00807). The authors thank the parents and children whose participation made this research possible.

\section{REFERENCES}

American Psychiatric Association. (1994). Diagnostic and statistical manual of mental disorders (4th ed). Washington, DC: Author.

Bartsch, K., \& Wellman, H. M. (1995). Children's talk about the mind. New York: Psychological Corporation.

Bayley, N. (1969). The Bayley Scales of Infant Development. New York: Psychological Corporation.

Bishop, D. V. M., \& Edmundson, A. (1987). Specific language impairment as a maturational lag: Evidence from longitudinal data on language and motor development. Developmental Medicine and Child Neurology, 29, 442-459.

Bretherton, I., \& Beeghly, M. (1982). Talking about internal states: The acquisition of an explicit theory of mind. Developmental Psychology, 18, 906-921.

Fischel, J., Whitehurst, G., Caulfield, M., \& DeBaryshe, B. (1989). Language growth in children with expressive language delay. Pediatrics, 82, 218-227.

Gardner, M. F. (1981). Expressive One-Word Picture Vocabulary Test. Novato, CA: Academic Therapy Publications.

Goffman, L., \& Leonard, J. (2000). Growth of language skills in preschool children with specific language impairment: Implications for assessment and intervention. American Journal of Speech-Language Pathology, 9, 151-161.

Hollingshead, A. A. (1978). Four-Factor Index of Social Status. Unpublished manuscript, Yale University.

Jenkins, J. M., Terrell, S. L., Kogushi, Y., Lollis, S., \& Ross, H. S. (2003). A longitudinal investigation of the dynamics of mental state talk in families. Child Development, 74, 905-920.

Johnston, J. R., \& Kamhi, A. (1984). Syntactic and semantic aspects of the utterances of languageimpaired children. Merrill-Palmer Quarterly, 30, 65-85.

Johnston, J. R., Miller, J., \& Tallal, P. (2001). Use of cognitive state predicates by languageimpaired children. International Journal of Language and Communication Disorders, 36, 349370.

Lee, E. C., \& Rescorla, L. (2002). The use of psychological state terms by late talkers at age 3. Applied Psycholinguistics, 23, 623-641.

Leonard, L. B. (1998). Children with specific language impairment. Cambridge, MA: MIT Press.

Leonard, L. B., Miller, C., \& Gerber, E. (1999). Grammatical morphology and the lexicon in children with specific language impairment. Journal of Speech, Language, and Hearing Research, 42, 678-689.

MacWhinney, B. (1991). The CHILDES language project: Tools for analyzing talk. Hillsdale, NJ: Erlbaum.

McKee, G., Malvern, D., \& Richards, B. (2000). Measuring vocabulary diversity using dedicated software. Literary and Linguistic Computing, 15, 323-337.

Owen, A. J., Leonard, L. B. (2002). Lexical diversity in the spontaneous speech of children with specific language impairment: Application of D. Journal of Speech, Language, and Hearing Research, 45, 927-937.

Paul, R. (1996). Clinical implications of the natural history of slow expressive language development. American Journal of Speech-Language Pathology, 5, 5-21.

Rescorla, L. (1989). The Language Development Survey: A screening tool for delayed language in toddlers. Journal of Speech and Hearing Disorders, 54, 587-599.

Rescorla, L. (2005). Age 13 language and reading outcomes in late-talking toddlers. Journal of Speech, Language, and Hearing Research, 48, 459-472.

Rescorla, L., Alley, A., \& Christine, J. B. (2001). Word frequencies in toddlers' lexicons. Journal of Speech, Language, and Hearing Research, 44, 598-609. 
Lee and Rescorla: Psychological state words

Rescorla, L., Dahlsgaard, K., \& Roberts, J. (2000). Late-talking toddlers: MLU IPSyn outcomes at 3;0 and 4;0. Journal of Child Language, 27, 643-664.

Rescorla, L., \& Lee, E. C. (2000). Language impairment in young children. In T. L. Layton, E. R. Crais, \& L. R. Watson (Eds.), Handbook of early language impairment in children: Nature. Albany, NY: Delmar.

Rescorla, L., Roberts, J., \& Dahlsgaard, K. (1997). Late talkers at 2: Outcome at age 3. Journal of Speech, Language, and Hearing Research, 40, 556-566.

Rescorla, L., \& Schwartz, E. (1990). Outcome of toddlers with specific expressive language delay. Applied Psycholinguistics, 11, 393-407.

Reynell, J. K. (1977). Reynell Developmental Language Scales. Windsor, Canada: NFER.

Ruffman, T., Slade, L., \& Crowe, E. (2002). The relation between child and mothers' mental state language and theory-of-mind understanding. Child Development, 73, 734-751.

Scarborough, H. S. (1990). Index of Productive Syntax. Applied Psychologinguistics, 11, 1-12.

Scarborough, H. S., \& Dobrich, W. (1990). Development of children with early language delay. Journal of Speech and Hearing Research, 33, 70-83.

Shatz, M., Wellman, H. M., \& Silber, S. (1983). The acquisition of mental verbs: A systematic investigation of first references to mental states. Cognition, 14, 301-321.

Sturn, A., \& Johnston, J. (1999). Thinking out loud: An exploration of problem solving language in preschoolers with and without language-impairment. International Journal of Language and Communication Disorders, 34, 1-15.

Tallal, P. (1988). Developmental language disorders. In J. F. Kavanaugh \& T. J. Truss, Jr. (Eds.), Learning disabilities: Proceedings of the National Conference (pp. 181-272). Parkton, MD: York Press.

Tardif, T., \& Wellman, H. M. (2000). Acquisition of mental state language in Mandarin- and Cantonesespeaking children. Developmental Psychology, 36, 25-43.

Thal, D., Tobias, S., \& Morrison, D. (1991). Language and gesture in late talkers: A 1-year follow-up. Journal of Speech and Hearing Research, 34, 604-612.

Watkins, R. V., Kelly, D. J., Harbers, H. M., \& Hollis, W. (1995). Measuring children's lexical diversity: Differentiating typical and impaired language learners. Journal of Speech and Hearing Research, 38, 1349-1355.

Watkins, R., Rice, M., \& Moltz, C. (1993). Verb use by language-impaired and normally developing children. First Language, 37, 133-143.

Windfuhr, K. L., Faragher, B., \& Conti-Ramsden, G. (2002). Lexical learning skills in young children with specific language impairment (SLI). International Journal of Language and Communication Disorders, 37, 415-432.

Young, E. C., \& Perachio, J. J. (1983). Patterned Elicitation Syntax Test-Revised. Tucson, AZ: Communication Skill Builders. 
Reproduced with permission of the copyright owner. Further reproduction prohibited without permission. 